\title{
Institutional developments in Greek linguistics
}

\begin{abstract}
In this piece, three items are presented that discuss recent developments in Modern Greek studies in three different academic institutions that have a positive impact on Greek linguistics.
\end{abstract}

\section{Keywords}

academia - Modern Greek studies - Modern Greek linguistics

In the past year or so, several academic institutions have created centers that provide an institutional home for different aspects of Greek studies on their respective campuses. These centers offer a home for, among other things, Greek linguistics. Thus, in this piece, these three developments are presented by way of showcasing these new centers and their potential for a positive impact on Greek linguistics.

\section{1 \\ The Greek Dialectology Lab at The Ohio State University}

In the summer of 2018, with the blessings of both the outgoing chair of the Department of Linguistics at The Ohio State University (osu), Shari Speer, and the incoming chair, Cynthia Clopper, an office in the department which had become vacant was designated as laboratory space and assigned to Distinguished University Professor of Linguistics Brian D. Joseph for his use. Using as a model the highly successful Laboratory of Modern Greek Dialects (http:/ lmgd.philology.upatras.gr) at the University of Patras, where he has visited on numerous occasions, he created the Ohio State University Laboratory for Greek

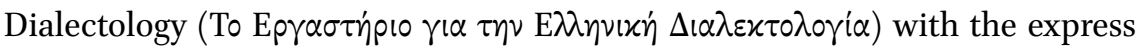
purpose of promoting the study of Greek dialects, both ancient and modern. The laboratory is located in room 120 Oxley Hall on the os campus. It houses a small collection of descriptive works on various Greek dialects, some of which

(C) BRIAN D. JOSEPH, IANTHI TSIMPLI, TIM WHITMARSH, ANASTASIA GIANNAKIDOU AND STEFANOS KATSIKAS, 2019 | DOI:10.1163/15699846-01902008 
were donated to Professor Joseph many years ago by the late Brian Newton of Simon Fraser University, a Neo-Hellenist linguist of the highest order, and others of which were in Professor Joseph's personal holdings, as well as a number of lexicographical resources, including several large dictionaries of Modern Greek and various etymological dictionaries. In addition, there is a computer on which are stored recordings of the Greek of southern Albania, as described below.

The Laboratory is home to several dialectological projects, undertaken by various of its faculty and students members, in the us and abroad. These projects are:

1. Study of the Greek spoken in southern Albania, especially in town of

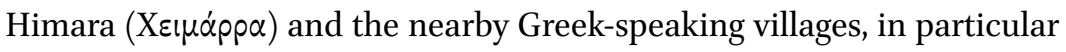
Palasa $(\Pi \alpha \lambda \alpha \dot{\sigma} \sigma \alpha)$ and Dhërmi $(\Delta \rho u \mu \alpha \dot{\delta} \varepsilon \varsigma)$; this project has been undertaken by local members of the Laboratory-Brian Joseph, Christopher Brown, Rexhina Ndoci, and Carly Dickerson - together with colleagues from abroad (Foreign Corresponding Members Alexander Novik, St. Petersburg, Russia; Andrey Sobolev, St. Petersburg, Russia; Aristotle Spirou, Athens, Greece; and Maïlinda Spirou, Athens, Greece). A number of fieldwork trips have been made to the area allowing for digital audio recordings of samples of the local dialect and elicitation of forms and information from consultants there. Several publications have already emerged from this work, including the "Field Report" in this issue of the journal.

2. Working with the materials on the dialect of Kephallonia collected by Renée Kahane that were donated by her son, Charles Kahane to the Laboratory; there are eight boxes of materials, mostly lexicographic in nature that Dr. Kahane, a native of the island and a linguist of long-standing associated with the University of Illinois up into the 1970s, collected primarily in the 1940s and 195os. Cataloguing these materials is the first task before us in the laboratory; Visiting Student Fellow Michalis Marinis of the University of Patras began work on this project during his February 2019 visit and it is expected that a student from the Modern Greek program here at osu can continue the work in 2020.

3. Developing, via a website (https://u.osu.edu/greek/), a resource for teaching and study of the Greek language in all its chronological phases, a project spearheaded by Christopher Brown and Foreign Corresponding Fellow Dr. Jerneja Kavčič (University of Ljubljana, Slovenia) with assistance from Director Brian Joseph.

4. Via a partnership between Brian Joseph and Yiorgo Anagnostu, Christopher Brown, and Stavros Constantinou of osu's Department of Classics, studying the Greek of Ohio, through surveys and interviews with mem- 
bers of the Greek communities in various parts of Ohio, including especially Columbus and the Akron-Canton area.

To inaugurate the laboratory, a conference on Greek linguistics was held on 910 February 2019, the 8th Midwest Workshop on Greek Linguistics, continuing the nearly annual conference organized by the Midwest Consortium on Greek Linguistics and referred to in the University of Chicago's "Polyhedric Greece" item in this piece. Nineteen papers were given by faculty and students from osu and other us institutions (University of Chicago and University of Pittsburgh) and by international visitors to the laboratory. As it happened, the first day of the conference coincided with International Greek Language Day.

Later in the year, in April, the annual Kenneth E. Naylor Memorial Lecture, sponsored by Professor Joseph in his role as the Kenneth E. Naylor Professor of South Slavic Linguistics but under the auspices of the laboratory as well, was delivered by Professor Panayiotis Pappas of Simon Fraser University. Professor Pappas, who holds a Ph.D. from osu (2001) and has written on the Greek of Columbus, spoke on "Greek Dialect Features in the Speech of Greek Canadians: An Unexpected Treasure Trove", discussing a research project he has been involved in studying the speech of Greek immigrants in Canada.

Prospects for the future of the laboratory are rosy. The abovementioned projects will all be advanced, and we will welcome more international visitors in the coming years. Professor Mark Janse of Ghent University, for instance, will be the Naylor lecturer in April of 2020, speaking on "From Katpatuka to Yunanistan: The Rise, Demise and Reawakening of Cappadocian Greek".

This laboratory represents an exciting development for the study of Greek dialects and the deliberate decision not to specify the time period in question is a signal that both ancient and modern dialects are fair game for laboratory projects. It is hoped that partnering with other Greek dialectologists and Hellenists around the country and around the world, as well as with the robust Modern Greek Studies program here at osu and the Department of Classics more broadly, will mean that this lab, and the work that will emanate from it, can serve as a lasting monument to the importance of the Greek language both to humanistic studies in general and to Modern Greek studies, and to the importance of Greek dialects to understanding the richness of the Greek language over all of its historical periods.

All interested readers are invited to visit the laboratory's website, at https://u .osu.edu/greekdialectology/ for more information on the lab, on its personnel, and on its various projects.

\author{
Brian D. Joseph \\ The Ohio State University \\ joseph.1@osu.edu
}




\subsection{Preamble}

Cambridge University has launched a new Centre for Greek Studies, dedicated to expanding the study of Greek language and culture across time and space, through research, debate and dialogue.

Greekness is often seen as a linear 'tradition' connecting the classical past to the present. This new centre aims, by contrast, to focus on its centrifugality and plasticity.

Greek culture is exceptional in that it can be studied in detail and depth over a period of 3000 years, and across a vast space. Already in antiquity it was a global culture, reaching from India to Italy, and from North Africa to Germany. These days, Greek speakers and Greek influence can be found on every inhabited continent. Greek culture takes many forms too: it is not just about politics and literature; it is also about art, literature, music, dance, technology and much more. Culture can, clearly, be mediated, transferred and changed through language.

More than this, Greek culture has been-uniquely in the West-for most of its lifetime a classical culture, one craved and emulated by others. This has been both its blessing and its curse. Greek precedents have inspired many people to be better, more creative and more just. But they have also fed into discourses of power and empire. The shifting contours of Greekness over time and space offer an unparalleled window onto not only the creativity of human beings, but also their darker side. Greek culture has enabled predatory, imperial mindsets - and, paradoxically, that depredation has often ended up being inflicted on the Greek world itself.

\subsection{The current state}

Cambridge has a proud history of Greek studies: it has seen a succession of brilliant Hellenists over the ages (including Richard Bentley, Richard Porson, Jane Harrison and A.E. Housman). In the 21st century, its success has continued: the Faculty of Classics has been top-ranked in the UK in recent research exercises, and its teaching top-ranked in the $\mathrm{UK}$ in the Guardian league table since 2012. Greek is also taught and researched in the Faculty of Divinity, another stellar department.

Studies in Modern Greek, established in the University in 1936 have been part of the provision offered in the Faculty of Modern and Medieval Languages — now called Faculty of Modern and Medieval Languages and Linguisticsfrom 1989 onwards. Building on the reputation of its significant scholarly activi- 
ties, Modern Greek studies continue to flourish with a stable student enrolment and substantial outreach activity. In the 2008 Research Assessment Exercise, the joint submission of the Modern Greek Section and the Faculty of Classics was recognised as the strongest in the $\mathrm{UK}$ for the assessment unit of Classics, Ancient History, Byzantine and Modern Greek Studies.

The Cambridge Centre for Greek Studies will draw on the resources built up through the University's goo years of existence. It will also, however, work with others around the world, facilitating new collaborations that will both explore the historical importance of Greece and its influence throughout the ages and look to the future, with the aim of contributing to a just, resilient, intellectually self-aware Hellenism.

\section{$2.3 \quad$ The vision}

The idea of a research and teaching centre specialising in Greek Studies was conceived by its two Directors, Professor Ianthi Tsimpli and Professor Tim Whitmarsh. Their vision is not just to unite the numerous disciplines which fall within the broad area of Greek Studies (language and linguistics, literature, art, history, archaeology, religion, society and politics across all chronological periods, from pre-history to the modern day, and across the entire Hellenic world) but also to provide a meaningful contribution to modern debates over nationalism, religion, ethnicity, Europeanism and heritage management.

The scholars united by the CCGS work in cognate faculties and departments across the University and the Colleges. The world of Humanities scholarship is changing, in several ways. Scholars no longer work in isolation, thinking great thoughts as they pore over tomes. The modern humanities scholar needs to think ambitiously about the big challenges that face us all: issues of identity, religion, gender, imperialism, regionalism, Europe and the East, populism, technology, sexuality and the environment, to name but a few. Such topics call for imaginative collaborations, not solitary study. If the Humanities are to prosper in the modern world, they need to address big, bold questions - and that means working together, across disciplines and outside of comfort zones.

Tim Whitmarsh, A.G. Leventis Professor of Greek Culture (and currently Acting Master of St. John's College), says of the Centre that “In this life you don't get many opportunities to shift the international conversation in a meaningful way. I sincerely believe that the Centre will be infinitely more than the sum of its parts. This is not just about connecting scholars working in disparate fields; it's about reimagining what Hellenism, classicism and even Europeanism are, and creating a progressive, inclusive agenda for the next generation."

The Centre's aims are in one sense unbounded, but there is a number of immediate, pressing aims. Currently in the UK, Cambridge and Oxford are 
now the only universities that offer teaching of Modern Greek at undergraduate level; Cambridge is by far the biggest provider, with a large and growing cohort, consistently attracting over 25 students each academic year. In the two optional papers, students are offered intensive language teaching that allows them to approach Modern Greek literature and culture in the original language. Through the examined works, they are able to gain a comprehensive idea of Modern Greek literary and cultural history, scrutinize the language through its many heritages, gain a broader perspective of Greece beyond the classical, and appreciate the universal resonance of the cultural output of contemporary Greece. The Centre aims to maintain and expand the study of the Modern Greek language, in combination with history, literature and culture at UG level, emphasising its links with different time periods. Building on this success is a major priority. Embedding Byzantine Studies-another field that is under threat in the Anglophone world-is also crucial.

The Centre will also promote the field of Greek linguistics. Cambridge is already reputed for its research in Greek dialectology, language development of Greek as a first and a second language and Greek as heritage language and culture. There are, currently, many academics throughout the university who are actively engaged in research in this field and the Centre will provide an opportunity for the sharing of thoughts and ideas, both within Cambridge and with the wider world. Professor Tsimpli, who is Chair of English and Applied Linguistics, said: "We intend the Centre to also promote the study of Modern Greek language and culture by including it in the 'Linguistics in M FL Project'; a joint venture between the University of Cambridge, Anglia Ruskin University and Queen Mary University of London. One of the aims of this project is to encourage exam boards to develop linguistic topics in MFL A-level syllabuses, such as 'history of the language' and 'regional linguistic variation.'"

The Centre will also disseminate and promote Greek culture to the population at large through a variety outreach activities and cooperation with other relevant stakeholders. Ideas include participation in the Cambridge Festival of Ideas, an annual event, now in its 12th year, which encourages the public to engage with the University through a series of mostly free events. Another initiative will see the CCGS partner with the Fitzwilliam Museum in a series of events in honour of the Bicentenary of the Greek revolution, including a symposium in Athens (in collaboration with the British School at Athens) and the "Being an Islander Exhibition", opening September 2021.

The Directors are committed to broadening interest in and reenergising the subject by reaching out to people who would not normally think of Greek Studies as interesting or relevant to them. It will exploit the opportunities of all forms of communication, especially web-based and social media. 
The CCGS received enthusiastic support from academics and politicians on its launch. His Excellency Mr Dimitris Caramitsos-Tziras, Greek Ambassador to the UK, described it as a "very important event and initiative". In his address at the Centre's launch, the ambassador stated that the inception of the CCGS "marks the beginning (some may say the rebirth) of the effort to introduce into the renowned and dynamic curriculum of this prestigious institution, the dedicated study of a language and a culture, that have a historical and universal presence throughout the spectrum of world civilization, science and human development." It "could not have come at more opportune time for Greece," he added.

His Excellency Mr Euripides Evriviades, High Commissioner for the Republic of Cyprus, described the establishment of the CCGS as "A decisive step for the promulgation of diachronic and ecumenical ideas of the classics."

Professors Tsimpli and Whitmarsh are eagerly anticipating growth of the Cambridge Centre of Greek Studies over the coming years. They welcome contact by prospective collaborators.

\author{
Ianthi Tsimpli \\ University of Cambridge \\ imt2o@cam.ac.uk \\ Tim Whitmarsh \\ University of Cambridge \\ tjgwroo@cam.ac.uk
}

\title{
3 Polyhedric Greece: the Center for Hellenic Studies at the University of Chicago
}

The study of Greek has been part of the instructional and research mission of the University of Chicago since its founding. In the Department of Linguistics, the Greek language has been studied for many decades since the arrival of Prof. Kostas Kazazis in the 1970s, and it took on a new dynamic and a theoretical focus more recently with Anastasia Giannakidou and Jason Merchant joining the faculty in 2001. The Linguistics Department has produced a number of $\mathrm{PhD}$ dissertations that address aspects of Greek morphology, syntax, semantics, variation and historical linguistics, and organized the 9th International Conference on Greek Linguistics (ICG L 9) in 2009 - the only ICG L to have ever taken place in the Us. Linguistics has been offering courses in Modern Greek language since 2012 at elementary and intermediate levels. 
Greek Linguistics in Chicago has a long-standing partnership with Greek Linguistics at Ohio State University (OSU), making Chicago a center for the Greek language in the Midwest. Anastasia Giannakidou, Jason Merchant, and Brian Joseph established the Midwestern Consortium on Greek Linguistics in 2009. The Consortium has organized a workshop almost every year since 2010, creating a vibrant and diverse community of scholars of Greek Linguistics and Greek language teaching with a strong sense of commitment to the study and promotion of Greek. At the same time, colleagues in other disciplines at the university—Classics, Philosophy, Art History, History, the Divinity School, Political Science and related disciplines-engage with the various other aspects of the Greek world. The university has a thriving program in ancient Greek, and operates a spring quarter civilization course abroad in Athens. A long list of faculty is involved in teaching, research and course offerings that relate to Greece, and explore past and current perspectives on Hellenism.

For a number of years now, it has become clear that the study of Greek language and Greek culture cannot remain 'segregated', and that faculty with shared interests in different fields lacked an organizational structure that could produce truly interdisciplinary work on Greece. The fragmentation impeded collaboration, integrative research, and potential advising and mentoring of students. After many years of efforts, on 1 July 2019, the Dean of the Division of Humanities, Anne Walters Robertson, established the Center for Hellenic Studies to fill this gap, and appointed Anastasia Giannakidou as the inaugural Director of the Center. The Center's advisory board consists of Stefanos Katsikas (Linguistics), Alain Bresson, Jonathan Hall and Sofia Torallas Tovar (Classics).

On Nov. 8-9, the Center was officially launched with a conference entitled Polyhedric Greece: The Many Faces of the Greek World. The Oriental Institute opened the doors to its beautiful space to host the event, which attracted a large audience, with members not just from the University, but also from the Greek community in Chicago. The Greek Counsel General Mrs. Katerina Dimakis and the Cook County Treasurer Mrs. Maria Pappas offered enthusiastic greetings at the opening; Dean Robertson, Clifford Ando (Chair of Classics) and Jason Merchant, as the Vice Provost for Academic Affairs, also offered their congratulations. Anastasia Giannakidou, in her opening remarks, outlined the vision and potential of the Center.

The new Center aspires to build the paradigm of Hellenic Studies at the University. By Hellenic Studies we mean the interdisciplinary study of a continuous, unbroken tradition of language, ideas, literature, art, culture, and history that stretches back for more than three thousand years. Greece, in this sense, is a laboratory to study evolution, variation, and change in all the disciplines 
involved. We want to offer a forum for students and faculty who want to study this rich tradition, and to show how useful — and indeed relevant—Greek ideas are today. We hope to show that new knowledge and enlightened insights about language, social organization, and the human condition can be produced from sustained scholarly and intellectual engagement with Hellenic culture. Our perspective is inclusive: we view Hellenic culture as the union of its manifestations in space and time, and do not pose artificial or arbitrary breaks in it.

Another important goal of the Center is to build bridges between the University and the larger Greek community in the Chicago area and beyond. Chicagoland features the second largest concentration of people of Hellenic descent in the Us, but until now no connection has been made. We plan to pay special attention to the study of the Hellenic diaspora, and to highlight the largely unknown Greek experiences and identities that exist in the world today. In this, our scope is unique with respect to other existing Hellenic Centers in the us and Western Europe. We want to emphasize the importance of how language relates to the diaspora experience, and we plan to pay special attention to Heritage Greek. Zoe Gavriilidou (Democritus University of Thrace), in her talk Profiling Greek Heritage Speakers in Chicago, presented a first study of Heritage Greek spoken in Chicago based on work she did in Chicago last year. It becomes evident that both linguistic theory and educators of Greek can benefit from a deeper understanding of the properties of Heritage Greek. Our Hellenic Center will invest time and resources in building curricula and creating material for teaching Heritage Greek speakers at the University in partnership with the Democritus University of Thrace.

Christopher Brown from osu, in his presentation Teaching Greek in the critical period: Lessons from the Mohawks, offered a promising perspective on teaching Greek as a heritage or second language by discussing language revitalization programs implemented in the context of endangered indigenous languages in the Americas. Although the Greek language is by no means endangered since it is the official language of Greece and Cyprus, it is nevertheless a minority language in the diaspora, therefore subject to the consequences of this status. Brown offered innovative ways of enlivening language teaching, shared his experience of teaching at osu, and offered practical advice based on his many years of directing the Modern Greek language program at osU.

The central theme of the conference, as the title suggests, is the understanding of Greece as a broad and diverse concept: Greece has many dimensions and sides, it is polyhedric. The most obvious understanding of Greece is with reference to the continuity of the Greek language in the geographical space of the Greek peninsula, Crete and adjacent islands-and language was the main topic of one of the three sessions of the conference (the others being Polis and 
History). Greek is the language spoken by Bronze Age Greeks and the Greeks of the Homeric poems, late Minoans, the city states of Classical Greece, the Macedonian state of Alexander that expanded Greece to the East, the language of Byzantium (or, Eastern Roman Empire, as the Byzantines themselves called it); and Greek is, finally, the language of the modern nation-state founded in 1830 that ushered Greece into modernity. In the trajectory of Greeks through time, we find Greeks also in I wví $\alpha$ (Asia Minor) and Cyprus; Greeks navigated the seas of the world known to them in antiquity, the Mediterranean and the Black Sea, and Greeks founded cities in Egypt, Southern Italy and Sicily. Wherever they went, Greeks brought along with their language, also their worldview: their love of independence and self-government $(\pi \dot{\lambda} \lambda(\varsigma)$, the appreciation of reasoned inquiry, the pursuit of truth and knowledge, the concepts of $\alpha p \varepsilon \tau \dot{\eta}$ and $\alpha \xi i \alpha$ (virtue and merit), their ideals of just government, their art, their theater, their poetry.

Greek culture is highly valued and continued to evolve in the Roman era, acquiring a new dimension with the adoption of Christianity during the Byzantine times. The Eastern Roman empire had Greek as its official language in the affairs of state, law, and education. Greek is the language of the Christian New Testament. Christianity and Hellenism meet in the Byzantine world, which lasts for a thousand years. In 1453 Constantinople fell to the Ottomans, and the Greek world entered the period of colonization known as the 'Ottoman yoke' or

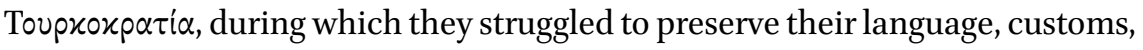
religion, and traditions - under continuous threat of life and discriminatory Jim Crow-like laws. The many centuries of subjugation contained numerous revolts by the colonized Greeks, until in 1821 they declare a war of independence that succeeds-leading to the formation of the modern Greek state. The Greek ideas of just government resurface in Greece's first constitution, which establishes democratic rule and upholds the principles of freedom and equality under the law. The Greek constitution of Epidaurus (1823) is the first in Europe to abolish slavery.

On the first day of the conference, Edith Hall (King's College London) presented a paper The Homeric Odyssey as Greek and World Literature Before and After Homer addressing the resonance and reception of the Odyssey in cultures beyond Greece. The adventures of Odysseus reflect, to a large extent, the tumultuous history of Greece itself. The context of Modern Greece's struggles from disasters to triumphs were further taken up in Stathis Kalyvas' (Oxford University) presentation in the Polis session What is Greece a case of? Kalyvas presented an optimistic outlook of Greece as an 'early late modernizer', a country ambitious beyond its means - which experiences, for this reason, recurring cycles of persistent indebtedness and default followed by rebounds that end up 
placing Greece at a better place each time. Despite impressions to the contrary, the Modern Greek society and economy have shown resilience in dealing with the current crisis.

Anthony Kaldellis, in the second presentation of the Polis session, Politeia: From Plato's Republic to Constantine's New Rome, offered discussion of how Greeks theorized the polity and put it into action over the course of two thousand years. The fundamental language used today in talking about politics relies on Greek terms such as politics itself and its cognates, which stem from the polis, the ideally self-governing, sovereign city-state. We also get from Greek the basic terms for designating particular types of regimes, such as monarchy, oligarchy, democracy, tyranny, including neologisms such as kakistocracy. This terminology classifies regimes based on who has power within them: one, the few, many, a good one, the worse one. In ancient Greek, the term $\pi 0 \lambda i \tau \varepsilon i \alpha$ is flexible: it can refer to citizenship, or to the government of a polis, but in Greek philosophy it refers to the form of a city's government, to its regime or constitution. Monarchy, democracy, and aristocracy are different types of politeiai in this sense.

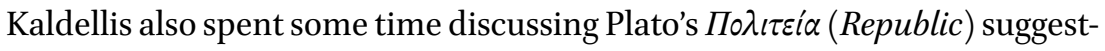
ing an interpretation where the По $\lambda \iota \tau \varepsilon i \alpha$ is not utopian discourse, but a treatise on how an intellectual community must be best organized. From this perspective, По $\lambda ı \tau \varepsilon i \alpha$ has enduring relevance on the principles that should guide good government in modern academy - among others, the predominance of inquiry and reason, equality of the sexes. The Byzantines, Kaldellis emphasized, never forgot Plato's Republic. Indeed, "the only reason we have Plato today is because they preserved him. For ten centuries, Byzantine scribes copied all his works, losing none, until the Italian humanists got a hold of them in the fifteenth century, read them, and were thoroughly scandalized. This great philosopher, whom they knew only through stray references in Cicero and Augustine, had preached the abolition of property? The equality of women? It took a while for the west to get over the sheer shock of reading Plato in the original." As can be seen, Greece — as a polyhedric intellectual space—offers ideas that are highly contemporary, and resonate with modern concerns about the role of academy, excellence, and equality. Demetra Kassimis (University of Chicago) offered insightful commentary.

Polyhedric Greece closed with a section on the history of Greeks of Asia Minor. We chose to concentrate on this topic because it is a darker aspect of Greek history, and largely unknown in the us. The loss of Asia Minor and the plight of Greek refugees has been decisive in the formation of the character of the Modern Greek state-Greece, a country of five million, accepted in 1922 more than one million refugees from Asia Minor, Thrace and Pontos 
(jointly referred to as Asia Minor here). As is well known, Greeks continued to live under Ottoman rule in the great cities of Smyrna, Constantinople, Trebzon and countless others for almost a hundred years after the Greek revolution in 1821. Theodosios Kyriakidis (Aristotle University of Thessaloniki) offered a brief overview of the three thousand-year history of the Greek communities of the Black Sea and Asia Minor. Those communities were targeted, persecuted, and eventually annihilated — along with Armenian and Assyrian communities - during a ten-year genocidal campaign by Turkish nationalists (1913-1923). Those that survived fled as refugees in Greece after 1922. The conference ended with a private screening of a new documentary Lethal Nationalism, created by the Asia Minor and Pontos Hellenic Research Center (AM PHRC), an institution based in Chicago that is devoted to documenting and studying this period. The founder and director of the AMPHRC, Mr. George Mavropoulos, along with Mr. John Davis, a member of the executive committee of the AMPH RC responsible for the documentary, offered commentary on the activities of their center including publications on the issue of the genocide.

As we move forward, the Center's future goals include establishment of an interdisciplinary undergraduate Minor in Hellenic Studies, as part of the Center's activities: the Minor will be designed to incorporate courses across divisions and schools, allowing a student to combine the study of the language with history, literature, and other fields. The Center will aim to create some specific courses for the Minor on Greek literature, the Byzantine world, and related topics. We also hope to partner with other institutions and organizations of the Greek community in Chicago (the National Hellenic Museum, the Panhellenic Scholarship Foundation, the Greek Orthodox Metropolis of Chicago, the Hellenic American Leadership Council) as well as with non-Greek organizations (e.g. Chicago Council on Global Affairs, the Chicago Art Institute, the Field Museum) to organize and co-sponsor events in order to increase the visibility of Hellenism and Hellenists in Chicagoland and beyond.

\author{
Anastasia Giannakidou \\ University of Chicago \\ giannaki@uchicago.edu \\ Stefanos Katsikas \\ University of Chicago \\ skatsikas@uchicago.edu
}

